\title{
A FALA EM FERDINAND \\ DE SAUSSURE: FACULDADE E EXERCÍCIO DA LINGUAGEM
}

Micaela Pafume Coelho*

(D) https://orcid.org/0000-0001-7734-7633

Como citar este artigo: COELHO, M. P. A fala em Ferdinand de Saussure: faculdade e exercício da linguagem. Todas as Letras - Revista de Lingua e Literatura, São Paulo, v. 22, n. 2, p. 1-10, maio/ago. 2020. DOI: 10.5935/1980-6914/eLETDO2013123

Submissão: fevereiro de 2020. Aceite: maio de 2020.

Resumo: A fala é um conceito saussuriano sobre o qual há poucas definições diretas, no seio das elaborações de Saussure, mas que permite ser caracterizado de forma relacional, a partir da lingua e da linguagem. Contudo, ainda assim restam algumas questões referentes à delimitação desse conceito; é possível, por exemplo, cogitar uma aproximação terminológico-conceitual entre o conceito de fala e as noções de faculdade e de exercício da linguagem. Considerando isso, neste trabalho, procuraremos investigar, em alguns documentos de Saussure, quais as relações possiveis entre o conceito de fala e as noções de exercício da linguagem e de faculdade da linguagem.

Palavras-chave: Fala. Faculdade da linguagem. Conceito. Saussure. Curso de Linguistica Geral. 


\section{INTRODUÇÃO}

$\boldsymbol{F}$ erdinand de Saussure ministrou três cursos de Linguística Geral na Universidade de Genebra entre os anos de 1907 e 1911. A informação de que o conteúdo desses três cursos resultou na edição do Curso de Linguística Geral (CLG) é bastante conhecida entre aqueles que se dedicam aos estudos linguísticos e tem trazido, ao longo do último século, diversos questionamentos e inquietudes. Os mais recorrentes são aqueles que circundam a problemática da autoria e da legitimidade da edição, tendo em vista as circunstâncias de sua elaboração. Apesar da grande discussão em torno dessas questões, neste trabalho não nos ateremos a elas.

Tomaremos, em contrapartida, o CLG como uma edição cuja autoria pode, de fato, ser atribuída a Saussure, pautando-nos em considerações já estabelecidas em trabalhos anteriores (cf. COELHO, 2019). Nesse sentido, o foco da discussão que aqui propomos será uma questão terminológico-conceitual que paira sobre um dos elementos que mais se destaca nas elaborações de Saussure: a fala.

No terceiro curso ministrado por Saussure, ocorrido entre 1910 e 1911, o linguista fizera, em seu início, a apresentação e a divisão dos assuntos que buscaria tratar. Entre esses assuntos, estava a "faculdade e exercício da linguagem pelos indivíduos"1 (SAUSSURE apud CONSTANTIN, 1993 [1910-1911], tradução nossa). Porém, talvez pela limitação de tempo, não foi possivel que Saussure o abordasse durante seu terceiro curso. Entretanto, Bally e Sechehaye, os editores do CLG, afirmam que o que havia sido prometido aos ouvintes do terceiro curso era um estudo sobre a Linguística da fala:

A ausência de uma "Linguística da fala" é mais sensível. Prometida aos ouvintes do terceiro curso, esse estudo teria tido, sem dúvida, lugar de honra nos seguintes; sabe-se muito bem por que tal promessa não pôde ser cumprida (BALLY; SECHEHAYE, 2006 [1916], p. 4, grifo nosso).

Uma breve análise de alguns documentos disponiveis a respeito do conteúdo do terceiro curso nos mostra que o estudo que foi prometido e não cumprido, durante o curso, foi justamente o que se refere à abordagem de Saussure sobre a faculdade e o exercício da linguagem pelos indivíduos. Afirmamos isso, pois esses mesmos documentos nos mostram que, embora o linguista tenha planejado abordar esse assunto ao longo de seu curso, ele nunca chegou a fazê-lo. O conteúdo de suas aulas se limita à abordagem das línguas e da língua. Todavia, uma vez que a fala consiste no lado individual da linguagem, cremos que seja possivel estabelecer uma relação entre ela e a faculdade e o exercício da linguagem pelos indivíduos.

Apesar da possibilidade dessa relação, nos questionamos se essas três noções - isto é, de fala, faculdade da linguagem e exercício da linguagem - podem, de fato, ser tomadas como equivalentes, sem ressalvas, no seio das elaborações de Saussure, ou se seu uso irrestrito ocasiona implicações teóricas. Além disso, considerando que os editores do CLG parecem utilizar, sem restrições, essas noções como sinônimas, levantamos as seguintes questões: qual a orientação terminológico-conceitual do CLG, no que diz respeito ao uso das expressões "fala", 
"faculdade da linguagem" e "exercício da linguagem"? Elas são usadas como equivalentes? Há a preferência de uma delas sobre as outras?

A fim de refletirmos sobre essas questões, realizaremos a análise de três materiais: 1. as anotações de É. Constantin acerca do terceiro curso de Saussure, editadas e publicadas por E. Komatsu e R. Harris no livro Troisième Cours de Lingistique Générale (1910-1911) - d'aprés les cahiers d'Émile Constantin; 2. o conjunto de manuscritos Notes pour le cours III, referentes às anotações de Saussure sobre seu terceiro curso; e 3. o próprio CLG. Contudo, antes de passarmos à análise desses documentos, no tópico a seguir discorremos um pouco sobre a relação entre as noções-alvo de nossa reflexão no arcabouço teórico saussuriano.

\section{OS ENTORNOS DA FALA}

Uma das inúmeras peculiaridades da teorização de Saussure é a diversidade terminológica que circunda cada um de seus conceitos. Essa diversidade, resultado de uma teorização em processo e de caráter não teleológico, aparece em diversos momentos das elaborações do linguista, em diferentes documentos que a atestam, e pode ser percebida mesmo se considerarmos unicamente o CLG. Por exemplo, na edição, é possivel observar o percurso de delimitação terminológico-conceitual do signo linguístico e de seus elementos componentes.

Em um primeiro momento, Saussure (2006 [1916], p. 81) delimita o signo como a união entre conceito e imagem acústica: "chamamos signo a combinação do conceito e da imagem acústica: mas, no uso corrente, esse termo designa geralmente a imagem acústica apenas, por exemplo, uma palavra (arbor etc.)". Entretanto, em um outro momento, o linguista opta por restabelecer a designação desses conceitos:

A ambiguidade desaparecia se designássemos as três noções aqui presentes por nomes que se relacionam entre si, ao mesmo tempo que se opõem. Propomo-nos a conservar o termo signo para designar o total, e a substituir conceito $e$ imagem acústica respectivamente por significado $e$ significante; estes dois termos têm a vantagem de assinalar a oposição que os separa, quer entre si, quer do total do que fazem parte (SAUSSURE, 2006 [1916], p. 81).

Apesar dessa reconfiguração terminológico-conceitual, muitas vezes o significante e o significado continuam sendo referenciados por meio das expressões "imagem acústica" e "conceito". Esse processo ocorre, também, com outros conceitos e noções que compõem a teorização de Saussure. Como exemplo, destacamos que, em alguns documentos do linguista, nota-se o uso do termo "discurso" com uma significação bastante próxima da noção de fala. Contudo, o uso desse termo de forma relacionada ao arcabouço teórico de Saussure é recorrentemente evitado, tendo em vista a "importância que adquiriu recentemente em alguns desenvolvimentos da linguística atual e por suas relações com outras disciplinas, especialmente a psicanálise” (ARRIVÉ, 2010, p. 115).

Entretanto, sua ocorrência nos documentos de Saussure, muitas vezes, reitera uma relação conceitual com a noção de fala, possivel de ser depreendida das reflexões saussurianas. Destaquemos o documento intitulado por Bouquet e Engler como "Nota sobre o discurso" (cf. SAUSSURE, 2002). Embora, na edição dos Escritos de Linguística Geral essa nota apareça de forma descontextualizada 
do todo do qual faz parte, segundo Testenoire (2016, p. 110), ela "[...] faz parte do conjunto de cadernos de anagramas elaborados por Saussure [...]". Além disso, o autor afirma que ela foi escrita contemporaneamente ao segundo curso do linguista - isto é, entre 1908 e 1909.

Nessa nota, podemos depreender - se não uma equivalência - uma relação entre as noções de fala e de discurso, uma vez que o discurso é descrito como "a língua em ação" e como o meio pelo qual a língua é criada. Ademais, de acordo com Testenoire (2016, p. 119), "nos dois primeiros cursos, discurso é empregado de duas maneiras: seja disposto ao lado de fala, de modo sinonímico, seja concorrentemente à fala [...]". Contudo, embora Saussure utilize o termo discurso em seus dois primeiros cursos e em outros de seus escritos, o autor ressalta que o termo está ausente do conteúdo do terceiro curso (TESTENOIRE, 2016, p. 118).

Como a análise que propomos é focada nos documentos que atestam a teorização de Saussure no momento de seu terceiro curso, consideramos pertinente ater-nos à relação entre fala, exercício e faculdade da linguagem - que é, de fato, a interseção que nos interessa. É importante destacar, desde já, que os trabalhos que versam sobre essa temática têm como foco, sobretudo, a relação da fala com a noção de faculdade da linguagem; o lugar do exercício da língua, em contrapartida, não é comumente retomado.

No CLG, a noção de fala pode ser depreendida a partir de sua relação com a conceituação de língua. Podemos considerar, inclusive, que essa noção possa ser definida de forma relacional, opositiva e negativa (COELHO; HENRIQUES, 2014). Desse modo, temos a fala como "um ato individual de vontade e inteligência" (SAUSSURE, 2006 [1916], p. 22) e como "manifestações individuais e momentâneas" (p. 28).

Segundo Arrivé (2010, p. 119), "a fala é reconhecidamente o objeto parcial do $4^{\circ}$ capítulo da 'Introdução', ao qual ela dá a segunda parte do título: 'Linguística da lingua e linguística da fala". Embora não ocupe, tanto quanto a língua, um lugar de prestígio no CLG, ainda assim a fala tem sua importância, principalmente no que concerne à delimitação da língua, por meio da exclusão, deste objeto, dos elementos pertencentes à fala. Dito de outro modo, dada a íntima relação que há entre língua e fala, como elementos pertencentes ao conjunto maior da linguagem, foi necessário que Saussure buscasse delimitar a língua tanto por meio da definição de seus princípios e de seus elementos como por meio da exclusão dos aspectos pertencentes à fala da caracterização da língua.

Arrivé (2010, p. 121) destaca que a fala possui três acepções possiveis, no arcabouço teórico saussuriano: 1. "o termo fala é frequentemente empregado no sentido de fonação"; 2 . "é utilizado com o sentido de 'ato consciente e intencional de encadeamento de unidades em uma sequência efetivamente realizada"; 3. "acumula em alguns casos os dois valores que acabamos de distinguir". De todas as formas, diferentemente da lingua, que se constitui como um sistema geral e que apresenta caráter social, a fala está sempre relacionada a um ato, e esse ato - seja ele considerado como fonação ou como uma acepção geral de fala - é sempre individual.

A faculdade da linguagem, por outro lado, segundo Arrivé (2010, p. 120), é o termo menos favorecido no CLG, tendo como base o uso dos termos "fala" e "discurso"; mas, segundo o autor, "[...] mesmo assim, ele aparece em uma entrada no índice, guarnecida por duas referências". Nesse sentido, Arrivé (2010, p. 120, grifo nosso) especifica que: 
Com efeito, o texto avança que "a lingua é um produto social da faculdade da linguagem". No aparato conceitual saussuriano, isso não é de todo falso. Mas corresponde apenas [...] a um dos dois aspectos da faculdade da linguagem. E é justamente o outro aspecto o que Saussure tinha em mente em sua afirmativa, como notou Constantin: "A língua será para nós o produto social cuja existência permite ao indivíduo exercer a faculdade da linguagem”.

No excerto anotado por Constantin e retomado por Arrivé, percebemos um indício de diferenciação entre faculdade e exercício da linguagem. Ora, se a língua é o meio que permite que a faculdade da linguagem seja exercida, podemos depreender que a faculdade da linguagem seja uma possibilidade de todos os indivíduos, e o ato individual dessa faculdade - ato este que se aproxima da noção de fala - é, na verdade, o exercício da linguagem.

Dessa forma, pode-se considerar o exercício da linguagem, e não a faculdade da linguagem, como noção equivalente à noção de fala. Mas essa é apenas uma das possibilidades. Arrivé destaca que, em alguns momentos da teorização de Saussure, é possivel compreender a última noção (a fala) como próxima à ideia de faculdade da linguagem. Contudo, o autor levanta uma ressalva:

Quer dizer que a faculdade da linguagem é apenas outro nome para a fala? Isso seria simples demais. A faculdade da linguagem é mais extensiva que a fala. Ela claramente engloba os atos de fala para os quais a lingua, estabelecida como instituição social, abre caminho. Mas ela abarca ainda o processo de constituição da língua (ARRIVÉ, 2010, p. 125).

Nesse sentido, percebemos que, para o autor, a faculdade da linguagem é uma noção que apresenta uma dimensão maior que a noção de fala, abrangendo tanto os atos individuais como também o processo de constituição da língua.

Assim, uma vez apresentada a discussão acerca da noção de fala e dos termos que a circundam na teorização de Saussure, no tópico a seguir passaremos à análise dos documentos saussurianos. Com essa análise, buscaremos destacar de que forma o conceito de fala e as noções de faculdade e de exercício da linguagem são delimitados nos materiais referentes, principalmente, ao terceiro curso do linguista. A partir disso, com o auxílio da edição crítica do CLG estabelecida por Engler (cf. SAUSSURE, 1968), será possivel compreender qual a orientação terminológico-conceitual do CLG no que tange ao uso desses termos e noções.

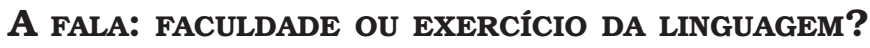

Iniciaremos nossa análise retomando a organização do terceiro curso, delimitada por Saussure em uma das aulas iniciais. Essa organização pode ser vislumbrada tanto por meio de suas notas manuscritas como também a partir das anotações de Constantin. Comecemos pelas notas manuscritas.

Ao anunciar as partes que comporiam seu curso, Saussure afirma: 
DOSSIE

Figura 1 - Primeiro excerto das Notes pour le cours III

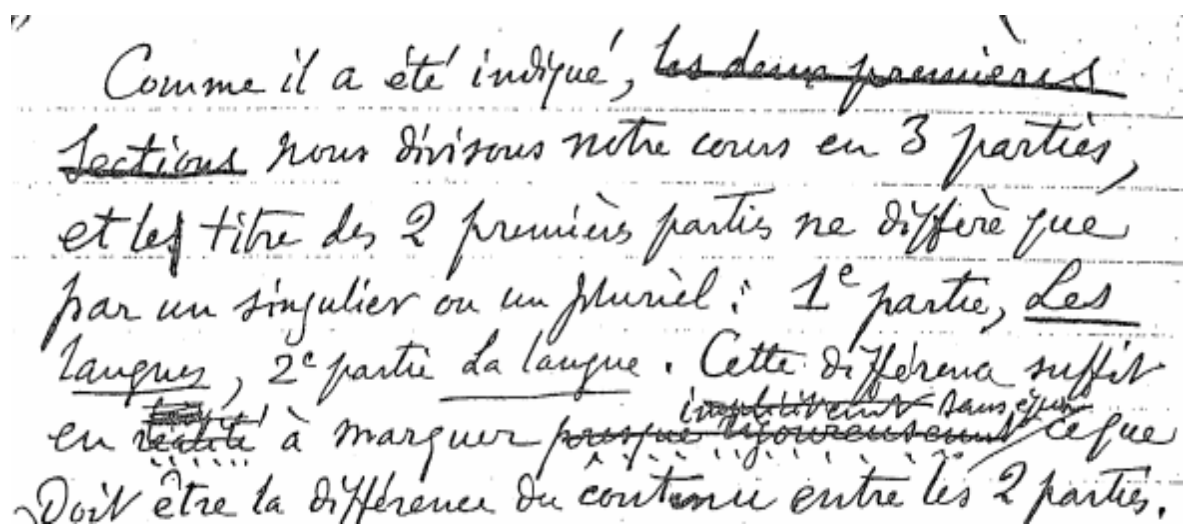

Como foi indicado, nas duas primeiras

seȩões, dividimos nosso curso em 3 partes,

e os título das 2 primeiras partes diferem apenas

por um singular e um plural: $1^{\text {a }}$ parte: $\underline{\text { As }}$

línguas, $2^{\text {a }}$ parte: A língua. Essa diferença basta

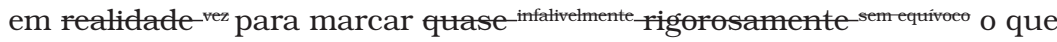

deve ser a diferença de conteúdo entre as 2 partes; ${ }^{2}$

Fonte: Saussure (1910-1911, f. 3).

Embora o linguista destaque que o curso seria composto por três partes, ele apresenta apenas duas: as linguas e a lingua. Uma análise das folhas que seguem, nesse conjunto de manuscritos, nos revela que a terceira parte do curso não foi anunciada por Saussure, em suas Notes pour le cours III. No entanto, as anotações de Constantin podem nos auxiliar a descobrir qual é a terceira e última parte prometida pelo linguista aos ouvintes do curso.

Em suas anotações, retomamos a seguinte organização proposta por Saussure: "Divisões gerais do curso: $1^{\circ}$ ) As línguas; $2^{\circ}$ ) A lingua; $3^{\circ}$ ) Faculdade e exercício da linguagem nos indivíduos"3 (SAUSSURE apud CONSTANTIN, 1993 [19101911], p. 6, tradução nossa). Nota-se que as duas primeiras partes apresentadas coincidem com aquelas expostas nas notas manuscritas; além disso, as anotações de Constantin nos permitem recuperar a última parte do curso: tratava-se da faculdade e exercício da linguagem nos indivíduos.

É importante destacar que não há ocorrência das expressões "faculdade da linguagem" e "exercício da linguagem", nas Notes pour le cours III. Há, contudo, algumas ocorrências do termo "fala". Destacamos a seguinte:

2 "Comme il a été indique, tes deux prmières sections nous divisons notre cours em 3 parties, et les titre de 2 premièrs parties ne diffère que par um singulier ou um pluriel: 1e partie, Les langues, 2e partie La langue. Cette différence suffit en fois realité à marquer presque re ce que doite être la différence du contenu entre les deux parties".

3 "Divisions générales du cours: $1^{\circ}$ ) Les langues $2^{\circ}$ ) La langue $3^{\circ}$ ) Faculté et exercice du langage chez les individus". 
Figura 2 - Segundo excerto das Notes pour le cours III

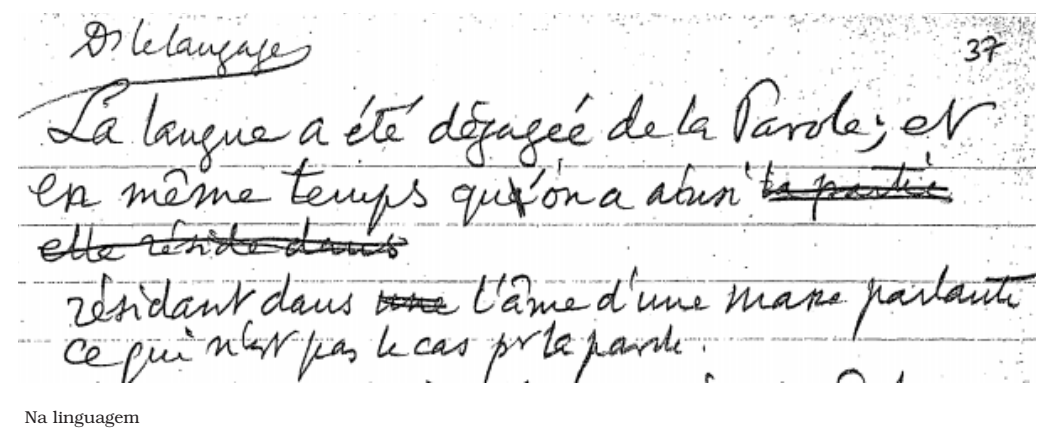

A língua foi separada da Fala, e ao mesmo tempo que nós $\mathrm{xxx}$ a parte ela reside na [ ] residente em um no âmago de uma massa falante o que não é o caso para a fala. ${ }^{4}$

Fonte: Saussure (1910-1911, f. 37).

Embora o termo "fala" seja mencionado no trecho acima, parece-nos que a preocupação maior de Saussure, nesse momento de suas elaborações, consiste em delimitar a língua. Nesse sentido, o linguista utiliza a fala como elemento de contraponto à língua, ou seja, define a última por meio da delimitação de suas diferenças com a primeira. Ousamos dizer que é, sobretudo, com essa função - de definir a língua por relação - que Saussure recorre à fala nesse conjunto de manuscritos. Isso pode ser notado, também, no seguinte momento do documento:

Figura 3 - Terceiro excerto das Notes pour le cours III

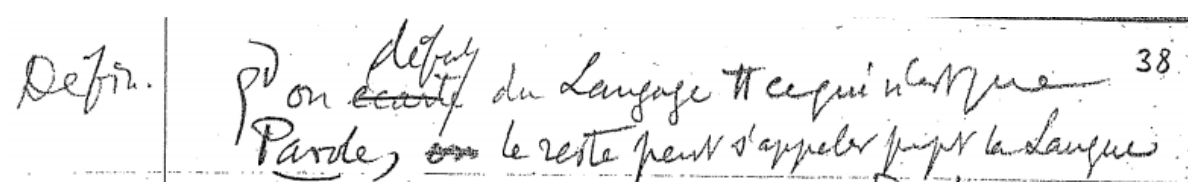

Definição

Quando exeluímos separamos da linguagem tudo o que não é

Fala, nós o resto pode se chamar xxx a língua. ${ }^{5}$

Fonte: Saussure (1910-1911, f. 38).

Como é possivel notar, em nossa análise do conjunto de manuscritos Notes pour le cours III, encontramos poucas ocorrências do termo "fala", e nenhuma que possa indicar uma definição própria desse conceito saussuriano. Além disso, reiteramos a não utilização das expressões "faculdade da linguagem" e "exercício da linguagem" no referido documento. Em contrapartida, nas anotações de Constantin, essas duas expressões são recorrentes e, além disso, é possível depreendermos a conceituação relacionada a elas:

\footnotetext{
4 "Dans le langage La langue a été dégagée de la Parole; et en même temps que'on a xxx ta partie elle réside dans [] résidant dans une l'âme d'une masse palante ce qui n'est pas le cas pr la parole".

5 "Définition Qd on écarte sépare du langage tt ce qui n'est que Parole, on le reste peut s'appeler xxx la langue".
} 
Essa faculdade nos é dada de início pelos órgãos, e após pelojogo que podemos obter a partir deles. Mas é apenas uma faculdade e seria materialmente impossivel de exercê-la sem outra coisa que é dada de fora ao indivíduo: a língua (SAUSSURE apud CONSTANTIN, 1993 [1910-1911], p. 6-7).

Considerando esse trecho das anotações de Constantin, podemos compreender que a faculdade da linguagem corresponde à possibilidade dos indivíduos, dada pelos órgãos e pelo seu jogo, de ter uma linguagem. Trata-se, a nosso ver, de uma faculdade físico-fisiológica, que, em conjunto com a língua, permite que ocorra, por parte dos indivíduos, o exercício da linguagem. Considerando essas concepções de faculdade e exercício da linguagem apresentadas nessas anotações, julgamos relevante retomar uma definição de fala, apresentada no CLG:

A fala é [...] um ato individual de vontade e inteligência, no qual convém distinguir: $1^{\circ}$ as combinações pelas quais o falante realiza o código da língua no propósito de exprimir seu pensamento pessoal; $2^{\circ}$ o mecanismo psicofisico que the permite exteriorizar essas combinações (SAUSSURE, 2006 [1916], p. 22).

A conceituação retirada do CLG destaca duas características componentes da fala: 1. uma psicofísica, que remete aos órgãos humanos e à sua capacidade de processamento, e que pode ser aproximada da definição de faculdade da linguagem apresentada nas anotações de Constantim; 2. outra que é constituída pelo uso da língua pelo falante, que pode ser aproximada da definição, anotada por Constantin, de exercício da linguagem. Nesse sentido, tal como conceituada no CLG, a fala parece englobar, ao mesmo tempo, a faculdade e o exercício da linguagem. Temos, aqui, mais uma possibilidade de entendermos a relação entre essas três noções.

A nosso ver, ao contrário da afirmação de Arrivé (2010, p. 125) de que a faculdade da linguagem é mais extensiva do que a fala, para nós, é a fala que se configura como tal. Assim, uma vez delimitado de que forma compreendemos as noções de fala, faculdade e exercício da linguagem, a partir dos documentos saussurianos, resta-nos retomar o uso, por parte de Bally e Sechehaye, em seu prefácio à primeira edição, do termo fala como equivalente da expressão faculdade da linguagem.

Como já afirmamos, os editores alegam que Saussure havia prometido um estudo sobre a fala; porém, analisando a organização do curso, percebemos que o que Saussure prometera havia sido um estudo sobre faculdade da linguagem e seu exercício pelos indivíduos. Ademais, a edição crítica de Engler nos mostra que há diversos trechos do CLG em que é utilizado o termo fala, porém, nas fontes correspondentes a esses trechos há a utilização da expressão "faculdade da linguagem". Isso pode ser percebido, entre outros momentos, no seguinte fragmento da edição crítica:

CLG: Quando separamos a língua da fala, separamos ao mesmo tempo [...].

Dégalier: Quando separamos língua de faculdade da linguagem, separamos [...]. Joseph: Quando separamos a língua da linguagem, separamos [...].

Constantin: Quando separamos a língua da faculdade da linguagem, separamos [...].

(cf. SAUSSURE, 1968, p. 41, tradução nossa, grifo nosso) ${ }^{6}$.

6 "CLG : En séparant la langue de la parole, on sépare du même coup [...] ; Dégalier : En séparant langue de faculté du langage, on a séparé [...] ; Joseph: En séparant la langue du langage on sépare [...]; Constantin : Quand on a séparé la langue de la faculté du langage, on a séparé $[\ldots] "$. 
É possivel notar que o fragmento do CLG que serve de base para as correspondências das fontes - que são os cadernos dos alunos dos cursos de Saussure consiste em um momento bastante relevante da edição. Trata-se do momento em que Saussure busca delimitar a língua, separando dela tudo que diz respeito à esfera da fala. Contudo, vemos que há uma discordância terminológico-conceitual entre a edição e suas fontes: não há, em nenhum dos excertos apontados por Engler, o uso do termo "fala"; em todos eles aparece a expressão "faculdade da linguagem".

Tal como ocorre no trecho supracitado, é possível que destaquemos outros momentos da edição em que há esse mesmo tipo de substituição. Como procuramos não nos delongar, não as exporemos nos limites deste trabalho; no entanto, elas podem ser resgatadas por meio da indicação feita por Engler (cf. SAUSSURE, 1968). Assim, tendo em vista o levantamento bibliográfico feito no tópico anterior a respeito das acepções de fala, faculdade e exercício da linguagem no arcabouço teórico saussuriano, bem como as análises feitas no presente tópico, consideramos pertinente questionar: a substituição da expressão "faculdade da linguagem" pelo termo "fala", na edição do CLG, pode ocasionar implicações teóricas?

Posicionamo-nos de forma a considerar que essas três noções (fala, faculdade da linguagem e exercício da linguagem) apresentam, em alguns momentos da teorização de Saussure, especificidades que permitem pensá-las como noções distintas. Apesar disso, são noções que apresentam uma proximidade teórica bastante grande, funcionando ora como elementos componentes ora como elementos agrupadores umas das outras. Sendo assim, admitimos que há uma flutuação terminológico-conceitual que envolve essas três noções, contudo, não acreditamos que seja possível estabelecer uma delimitação categórica de cada uma delas.

Essa impossibilidade é uma característica que provém da própria teorização de Saussure, sempre em processo e, a priori, sem vistas à criação de uma ciência. Por isso, acreditamos que o uso do termo "fala" como substituto de "faculdade da linguagem" e "de exercício da linguagem" não ocasione grandes implicações teóricas, e nem desautoriza a edição do CLG, uma vez que nenhum dos termos parecia estar categoricamente definido e delimitado no seio das reflexões de Saussure.

\section{CONSIDERAÇÕES FINAIS}

O propósito deste trabalho consistiu em investigar o tipo de relação existente entre a fala, a faculdade e o exercício da linguagem, procurando ressaltar qual a orientação terminológico-conceitual do CLG no que tange ao uso desses termos e noções. Para tanto, perpassamos os pos+icionamentos de Arrivé (2010) e Testenoire (2016) acerca dos usos e das acepções dessas expressões nas reflexões de Saussure. Depois disso, nos voltamos à análise de três materiais que compõem o corpus saussuriano: o CLG, as Notes pour le cours III e as anotações de Constantin, referentes ao terceiro curso.

Com essa análise, percebemos que a edição do CLG tende ao uso do termo fala, em lugares em que, nas fontes, é utilizada principalmente a expressão "faculdade da linguagem". Apesar disso, dada a não categorização conceitual dessas noções na teorização de Saussure, não consideramos que esse tipo de substituição possa desencadear grandes implicações teóricas. Tendo isso em vista, ousamos supor que não seja possivel definir se a fala corresponde à faculdade da linguagem ou ao seu exercício. A nosso ver, ambas as possibilidades são plausiveis. 


\section{Ferdinand de Saussure's concept of Parole: Faculty or EXercise of language?}

Abstract: Parole is a Saussurean concept about which there is few direct definitions within Ferdinand de Saussure's elaborations. However, this concept can be characterized in a relational way, from the definitions of langue and langage. Nevertheless, there are still some questions regarding the delimitation of this concept; it is possible, for example, to consider a terminological a terminological-conceptual convergence between the concept of parole and the notions of faculty and exercise of language. Considering this, in this work, we aim to investigate, in some of Saussure's documents, what are the possible relations between the concept parole, and the notions of exercise of language and faculty of language.

Keywords: Parole. Faculty of language. Concept. Saussure. Course in General Linguistics.

\section{REFERÊNCIAS}

ARRIVÉ, M. Em busca de Ferdinand de Saussure. Tradução M. Marcionilo. São Paulo: Parábola Editorial, 2010.

BALLY, C.; SECHEHAYE, A. Prefácio à primeira edição. In: SAUSSURE, F. Curso de Linguistica Geral. Tradução A. Chelini, J. P. Paes e I. Blikstein. 27. ed. São Paulo: Cultrix, 2006 [1916].

COELHO, M. P.; HENRIQUES, S. M. A fala em Ferdinand de Saussure: um conceito relacional, opositivo e negativo. Dominios de Lingu@gem, Uberlândia, v. 8, n. 1, p. 646-663, 2014.

COELHO, M. P. A autoria do CLG: uma análise à luz do conceito foucaultiano de função autor. Revista do GELNE, v. 21, n. 1, p. 166-177, jun. 2019.

SAUSSURE, F. de. Notes pour le cours III. In: Papiers Ferdinand de Saussure, 3951 - 22. Bibliotèque de Genève, 1910-1911. $56 \mathrm{f}$.

SAUSSURE, F. de. Curso de Linguística Geral. Tradução A. Chelini, J. P. Paes e I. Blikstein. 27. ed. São Paulo: Cultrix, 2006 [1916]. Cours de linguistique general. Charles Bally e Albert Sechehaye (org.). Colaboração de Albert Riedlinger, [1916].

SAUSSURE, F. de. Cours de Linguistique Générale. Édition critique par Rudolf Engler. Wiesbaden: Harrassowitz, 1968. Tome 1.

SAUSSURE, F. de. Troisième Cours de Linguistique Générale: d'après les cahiers d'Emile Constantin/Saussure's third course of lectures on general linguistics (1910-1911): from the notebooks of Emile Constantin. French text edited by Eisuke Komatsu and English text edited by Roy Harris. Oxford: Pergamon Press, 1993. SAUSSURE, F. de. Escritos de Linguistica Geral. Organização e edição S. Bouquet e R. Engler. São Paulo: Cultrix, 2002.

TESTENOIRE, P. Y. O que as teorias do discurso devem a Saussure. In: CRUZ, M. A.; PIOVEZANI, C.; TESTENOIRE, P. Y. (org.). Saussure, o texto e o discurso: cem anos de heranças e recepções. São Paulo: Parábola Editorial, 2016. p. 105-124. 